\title{
Analysis of Light Bulb Temperature Control for Egg Incubator Design
}

\author{
Aliza Che Amran ${ }^{1,3 *}$, Ahmad Muzaffar Abdul Kadir ${ }^{1,3}$, Ahmad Shukri Zainal', \\ Rozilawati Mohd Nor ${ }^{1,3}$, Sahazati Md. Rozali ${ }^{1,3}$, Saleha Mohamad Saleh ${ }^{1,3}$, \\ Ahmad Hadinata Fauzi ${ }^{4}$
}

${ }^{1}$ Faculty of Electrical and Electronic Engineering Technology,

Universiti Teknikal Malaysia Melaka (UTeM), Hang Tuah Jaya, 76100, Durian Tunggal, Melaka, MALAYSIA

${ }^{2}$ Faculty of Electrical Engineering,

Universiti Teknikal Malaysia Melaka (UTeM), Hang Tuah Jaya, 76100, Durian Tunggal, Melaka, MALAYSIA

${ }^{3}$ Center for Robotics and Industrial Automation (CERIA)

Universiti Teknikal Malaysia Melaka (UTeM), Hang Tuah Jaya, 76100, Durian Tunggal, Melaka, MALAYSIA

${ }^{4}$ Faculty of Computer Science and Information Technology,

Universiti Malaysia Sarawak (UNIMAS), 94300 Kota Samarahan, Sarawak, MALAYSIA

*Corresponding Author

DOI: https://doi.org/10.30880/ijie.2019.11.04.031

Received 8 August 2019; Accepted 26 August 2019; Available online 5 September 2019

\begin{abstract}
This paper explained the analysis and findings of using light bulb as a thermal source for an incubator system. The inner dimension of the incubator is $26 \mathrm{~cm}(\mathrm{~W}) \times 38 \mathrm{~cm}(\mathrm{~L}) \times 26 \mathrm{~cm}(\mathrm{H})$. In the experiment, a temperature sensor that measures the inside temperature of the incubator used as a feedback signal. To run the experiments, number of light bulbs and its type were determined. There are three types of bulb used i.e. Incandescent Light (IL Bulb), Compact Fluorescent Lamp (CFL Bulb) and Light Emitting Diode (LED Bulb). Three fixtures are proposed for each bulb type, i.e. one-bulb fixture, two-bulb fixture and three-bulb fixture. Apart from that, three control modes were tested, i.e. Mode 1, Mode 2 and Mode 3. Mode 1 is ON-OFF bulb control. Mode 2 is ON-OFF bulb control, as well as ON-OFF ventilation fan control. Finally, Mode 3 is only ON bulb control and ON-OFF ventilation fans The experimental results showed that, for the chosen incubator size, threebulb fixture IL-type light bulb controlled with Mode 3 control gave shorter time to reach the set point then return to set point after overshoot.
\end{abstract}

Keywords: Temperature Control, Incubator, IL bulb type, CFL type, LED type

\section{Introduction}

Poultry farming is the process of raising and breeding domesticated birds such as chickens, ducks, turkeys and geese for the purpose of farming meat or eggs as our food. Some chickens are bred for egg production and can lay as frequent as they can. Besides breed factor, egg production capability of a chicken also depends highly on chicken age factor [1]. As an egg hatcher, all these need to be considered if you are breeding the flock using the natural way.

From the view point of a productive farmer, automatic hatcher machine or known as egg incubator is an option to increase their breeding productivity via artificial incubation. An incubator basically is an enclosed structure with a fan 
and heater to keep eggs warm during the 21-day incubation period. Apart of keeping the incubator's temperature at certain temperature throughout the 21 days, these eggs are required to be physically turned and rotated, to prevent the developing chick from sticking to its shell. Only fertile eggs can be hatched using an incubator [1]. For small-scale farmers or novice farmers, a low cost egg incubator made up with minimal resources would be preferable. Many of the Do-It-Yourself (DIY) egg incubators, reported on the internet or observed been used in local communities, has applied light bulbs as the incubator's source of heat. There are many ways to generate heat inside the incubator. Besides heating coils, most of them used Incandescent Light (IL) bulbs as heating element for their incubator design. Lamp bulbs are preferred compared to others because they are cheaper and easy to be implemented.

This project is aimed to verify that IL bulb is the best light bulb in designing a low cost incubator. In this project, several types of light bulbs are chosen beside IL bulb. Its aim is to observe how these different types of bulbs performed in warming the incubator and most importantly maintaining the air temperature at the required value. Next, this project is aimed to identify the optimal number of light bulbs required to achieve better temperature control method. Two best light bulbs are chosen from the previous experiment findings. The project ran a number of experiments using those two light bulb types in order to figure out which set up gives the optimum performance for a low cost incubator.

Apart of being able to confirm the best bulb, findings of the experiments will be used in the next phase of this project. Usually, open-loop responses are analyzed to model the incubator system characteristics. Using the system model, researchers could propose controllers to achieve better transient responses and minimal steady state error for the temperature control system. There are many researches that perform study on open-loop response on passive systems in order to obtain system parameters such as vehicle damper system, couple tank system, and others [2]. One of them is Jason who has reported a modeling and control of a Tungsten-Bulb heated incubator [3]. Tungsten-bulb is also an incandescent lamp type. His experiments were used to teach control system syllabus for a general engineering program students. It would be beneficial if this project could be extended to be part of teaching control systems in our university, particularly on designing temperature control system.

\section{Literature Review}

\subsection{Egg Hatching Process}

An egg needs 21 days to hatch. A complete chicken embryo development could turn a fertilized chicken egg into a healthy chick. In many incubator's hatching strategies, heating and turning are the two most common features offered. This is because egg hatching requires these two steps to ensure the completion of the chicken embryo development. Wilson in his work studied the effects of egg warming and egg turning during the pre-incubation period on hatchability. He also reviews the optimum requirements of temperature and turning for hatchability in different species [7].

Table 1. The recommended hatching temperature based on number of days [6][4]

\begin{tabular}{lcc}
\hline $\begin{array}{l}\text { No. of } \\
\text { Day }\end{array}$ & $\begin{array}{c}\text { Temperature } \\
\text { (deg. Celcius) }\end{array}$ & Development \\
\hline $0-4$ & 38.2 & Tissue, heart, blood vessels and limb (brain, eye) \\
development starts.
\end{tabular}

His findings from this paper gave this project scopes to focus on. According to Wilson, the embryonic growth begins when the temperature is $24^{\circ}-27^{\circ} \mathrm{C}$ or above. Besides that, his studies also concluded that eggs warmed for short periods prior to incubation have slightly improved hatchability. The optimal incubation temperature is between $37^{\circ}$ and $38^{\circ}$, with variations for species, embryonic age, humidity and other factors; and Wilson also highlighted that high or low temperature during incubation results in disproportionate development, circulation disruption, abnormalities and reduced growth. It is also worth to decide the required temperature for this experiment is between $37^{\circ}$ and slightly 
above $38^{\circ}$. This requirement is also confirmed by Xinling [6]. The recommended temperature requirement according to the number of days is listed in Table 1. Exposing eggs to temperatures outside the desired range for an elongated period of time can cause failed hatches, altered hatch time and birth defects.

Interesting point to be highlighted is the result of a study experimented by a group of high school students and teachers of a Japanese High School, where they have managed to complete a chicken egg embryo development shelllessly. They transferred the chicken embryo out of the egg shell into a polymenthylpentene film and able to turn the embryo into a healthy chick after 21 days. The shell-less embryo however still need to be turned around during the growth process. The embryo still need to be incubated at a temperature of $38 \mathrm{oC}$ and maintained at a certain level of humidity. This shows that, regardless of what the embryo medium is, turning and controlling the heat and humidity are the critical features for developing egg embryo's development.

The scope of this project does not include turning and controlling humidity. Since this project experimented variables that are related to temperature control only, therefore it focused only on controlling the temperature.

\subsection{Temperature Control of Low Cost Egg Incubators}

There are many Do-It-Yourself (DIY) projects that build passive egg incubators using light bulbs and a thermometer. Most of them used Styrofoam as the incubator casing. For this kind of built, the user has made several ventilation holes around the casing. Usually these holes are made at a higher level of the casing. These holes serve their purpose to control the inside temperature of the incubator. Since hot air floats, placing these holes at the upper side of the incubator box would help the hot air to flow out naturally and passively without the requirement to have additional force to passage the hot air out. This passive incubator design requires the user to check on the temperature many times and manually close or open the holes to increase or decrease temperature respectively. This temperature control is very important because the chick embryo development is very sensitive to temperature.

When the temperature is too low, the user has to close or block almost all the ventilation holes. This way the air, that has been increased its temperature by the lamp bulb, will be able to be accumulated inside the incubator. Thus increases the temperature. It is advisable not to close the holes completely, as the eggs require certain level of humidity and ventilation to "breathe". When the temperature is too high, this means the air is too hot for the eggs and need to be reduced immediately. The blocked or covered ventilation holes are now be opened to passage the excessive hot air out of the box. This creates pressure difference between inside and outside of the incubator box. Due to the lower pressure of the inside box, outside air (which is much cooler) will flow into the box thus decreasing the incubator's temperature naturally. The manual temperature control can be improved extensively by implementing some automatic control strategy to it. This project will run temperature control experiments using ON-OFF control. Its purpose is to observe how the system respond while varying some experiment variables, such as number of bulbs and its types.

\subsection{Bulb Type}

Lumens per Watt shows how efficient a bulb is at converting power into light. Lumen measures the brightness or the amount of light emitted by the bulb. Meanwhile, Watt is the unit to measure the amount of power consumed by the bulb. Based on [10], LED bulb type is the most efficient bulbs at converting energy into light. This is followed by CFL type and lastly, IL bulb type. According to the LPW table, IL bulb type is not very efficient light bulb device. This bulb type could not convert a one Watt of power into much lumen. The IL type is able to convert one Watt into 14 lumens only. Compared to an LED bulb type, this kind of bulb has six times higher LPW, as it could convert one Watt of power into 84 lumens.

Table 1. Lumens per Watt (LPW) rating for different bulb

\begin{tabular}{llc}
\hline No. & \multicolumn{1}{c}{ Type Name } & LPW Rating [10] \\
\hline 1 & Incandescent Light (IL Bulb) & 14 \\
& & (for $60 \mathrm{~W}$ bulb) \\
2 & Compact Fluorescent Lamp (CFL Bulb) & 62 \\
& & (for $13 \mathrm{~W}$ bulb) \\
3 & Light Emitting Diode (LED Bulb) & 84 \\
& & (for $9.5 \mathrm{~W}$ bulb) \\
\hline
\end{tabular}

Based on law of energy conversation, energy can neither be created nor destroyed. It can only be transferred from one form to another. The energy that is not converted into lumens are converted into heat. This explains why IL bulbs are much hotter than CFL or LED bulbs. It is obvious that, for heating purposes, IL type will be chosen because of its ability to heat up a medium faster as compared other type of bulbs. The reason why this project investigates types of bulbs is because to observe the open loop response of the system when current is supplied. The project aimed to explore 
the optimal number of bulbs to be used for low cost incubator design. One of the findings of this project would be the number of bulbs required for optimal temperature control performance.

\subsection{System Modeling}

Temperature control is a process in which change of temperature of a space (and the objects inside the confined space) is measured. The passage of heat energy that goes inside or outside the space is controlled to achieve the desired temperature. To propose a controller, any systems could be modelled first. Using this method, its open loop response will be observed and analyzed. These open-loop results should be able to be used to derive controller's parameters and constants. Thermodynamic model for an incubator will involve a number of system parameters. One of them is thermal dynamics of the lamp bulbs. Different bulbs will have different thermal dynamic properties. According to Jason, he has suggested the number of bulbs as the open-loop gain of the incubator system. In his work, he conducted an open-loop experiment where only one bulb is used. In the incubator thermodynamic model, he has defined these as the thermal parameters as shown in Error! Reference source not found. [3]. Again, this paper will not derive the system's openloop characteristics yet. Instead, this paper would propose the variables for a good temperature control using lamp bulbs.

Table 3. Incubator System Parameters

\begin{tabular}{ll}
\hline Symbol, Unit & \multicolumn{1}{c}{ System Parameters } \\
\hline Qin & Heat (power) flowing in (input) \\
Tout & Outside temperature (input) \\
Tincub & Air temperature inside the incubator \\
$\mathrm{Cb}$ & Specific heat of bulb \\
\hline
\end{tabular}

\section{Methodology}

Generally, there are three objectives to be achieved in this project. They are listed as follow:-

Objective 1: To build an experiment setup to represent an egg incubator that uses light bulbs as its heating element.

Objective 2: To determine light bulb type and number of bulbs required for optimal temperature control.

Objective 3: To propose a control algorithm to maintain temperature inside the incubator.

The following explains the methodology opted for this project. There are two parts in this Section. The first part explains about the incubator design. It includes the physical assembly and the electrical and electronic circuitry. The second part details out the experiment design to determine the best bulb types to heat up the incubator and the best control method for the incubator temperature control.

\subsection{Incubator Design}

For the incubator design, this project have used a Styrofoam box as the incubator body. Its outer dimension is 30 $\mathrm{cm}(\mathrm{W}) \times 43 \mathrm{~cm}(\mathrm{~L}) \times 32 \mathrm{~cm}(\mathrm{H})$. The inner dimension is given by $26 \mathrm{~cm}(\mathrm{~W}) \times 38 \mathrm{~cm}(\mathrm{~L}) \times 26 \mathrm{~cm}(\mathrm{H})$. This box is sufficient for the project minimal design requirement. The experiments designed for this project require the incubator to reach one desired temperature set point chosen based on the literature survey. This scope is sufficient for data collection of this project. This incubator design may not be suitable to complete the hatching process for 21 days as it does not include humidity control and turning control. The setup is shown by Figure 1.

Three types of light bulb will be used in this experiment. Besides that, there are other components used for the experiment setup. Instead of a thermometer, the setup used a temperature sensor LM35 to measure the air temperature inside the Styrofoam casing. For active cooling, a number of CPU fans are used. In this setup, there are three small CPU fans (Fan) and one large CPU fan (Large_Fan) are assembled at the casing. Due to these fans, ventilation holes will not be necessary anymore (as mentioned earlier needed for passive temperature control). To control all these elements, Arduino Uno is used as the microcontroller. It is not only for control purposes; Arduino also enables researchers to perform data logging in real time. The components are controlled via programming and the measured temperatures were sent to the computer and recorded as experiment data. 


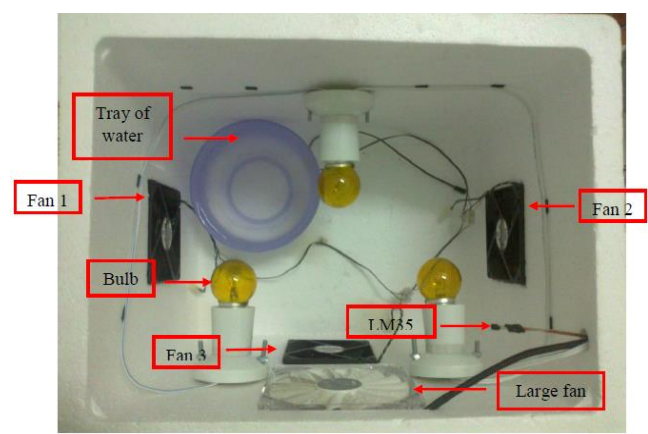

Fig. 1 - The experimental setup

\subsection{Experimental Setup}

There are three control modes used in this experiment. The control sequence for each mode are as follow:

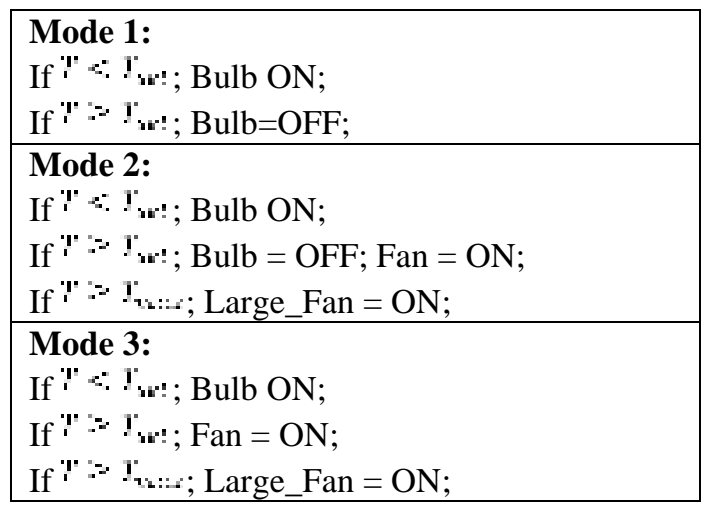

where $\mathrm{T}$ is the actual temperature measured inside the incubator, $\mathrm{T}_{\text {set }}$ is the desired temperature chosen as $37^{\circ} \mathrm{C}$, and $\mathrm{T}_{\max }$ is set as $39^{\circ} \mathrm{C}$. Only in Mode 3, the bulb is still $\mathrm{ON}$ when the fan is activated to pull down the temperature. In this experiment, there are a total of nine combination of experiment setups built in order to study the performance of the different light bulbs. For each light bulb type, there are three setups i.e. one, two and three light fixtures. These setups are explained using nomenclatures as shown by Table 4.

Table 4. Experiment's nomenclature

\begin{tabular}{cll}
\hline Light Bulb Type & No. of Bulb(s) & $\begin{array}{c}\text { System } \\
\text { Name }\end{array}$ \\
\hline \multirow{6}{*}{ IL } & 1 & IL1 \\
& 2 & IL2 \\
CFL & 3 & IL3 \\
& 1 & CFL1 \\
& 2 & CFL2 \\
LED & 3 & CFL3 \\
& 1 & LED1 \\
& 2 & LED2 \\
& 3 & LED3 \\
\hline
\end{tabular}

Initially, the experiments were run based on Mode 1 control. All readings were recorded. Secondly, the same experiment setups are used to run experiments using Mode 2, then using Mode 3. These results are listed in the next section.

\section{Results and Discussion}

As mentioned earlier, the first experiment will be run using control Mode 1. Control Mode 1 uses solely ON-OFF control of the light bulb(s). Table 5 shows the results. This table tabulates the best three results among the nine experiments. The time $t_{1}$ is the time taken to reach $T_{\text {set. Time }} t_{2}$ is the time where the system cool down to return to $T_{\text {set }}$ after overshoot. From this result, it is observed that the best type of bulb to control the incubator temperature would be type IL. The best performance is given by IL3. Since this project will also conduct experiment with different number of lamps, it is found that 2 IL bulbs (IL2) performed better than 3 CFL bulbs (CFL3). 
Table 5. Experimental results for Mode 1 control

\begin{tabular}{lcll}
\hline System & $\mathbf{t}_{\mathbf{1}}(\mathbf{s e c})$ & $\mathbf{t}_{\mathbf{2}}(\mathbf{s e c})$ & $\boldsymbol{\Delta} \mathbf{t}(\mathbf{s e c})$ \\
\hline IL3 & 46.78 & 64.78 & 18.00 \\
IL2 & 68.78 & 96.38 & 27.60 \\
CFL3 & 86.78 & 172.18 & 85.40 \\
\hline
\end{tabular}

Figure 2 shows the system responses for the three results i.e. IL3, IL2 and CFL3. The main difference among these three responses is how the system oscillates or regulates to control the temperature at Tset. System IL3 able to regulate more frequent in order to have better control maintaining the temperature at the desired level. This is because IL3 has faster transient response as it was able to reach the set point temperature in less than a minute, and shorter time to return to Tset. From the results, it is observed that Mode 1 control able to regulate the temperature. This is because the maximum temperature reached is $39.5{ }^{\circ} \mathrm{C}$ (for IL3 and IL2) and about $39{ }^{\circ} \mathrm{C}$ (for CFL3). As for the minimum temperature, it was about $36.5{ }^{\circ} \mathrm{C}$ for all three responses. These resulted in an average temperature of $37.5{ }^{\circ} \mathrm{C}$ to 37.8 ${ }^{\circ} \mathrm{C}$.

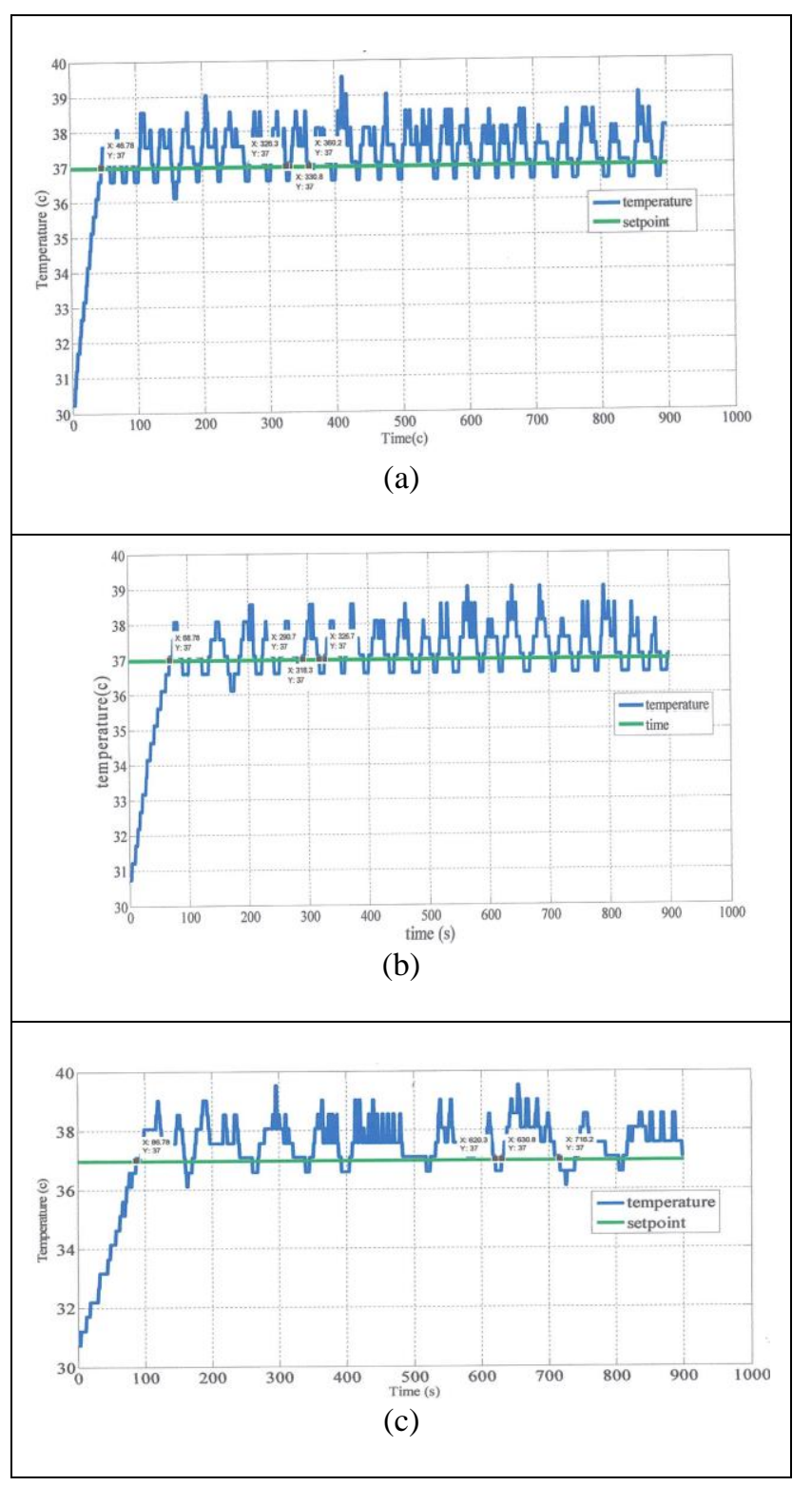

Fig. 2 - The experimental results for Mode 1 (a)IL3 System Response, (b) IL2 System Response, (c) CFL3 System Response 
This experiment is continued with other control strategy, i.e. Mode 2. Mode 2 is a control strategy where the system includes the control of ventilation fans, and it switches off the light bulb during cooling period. The results are shown in Table 6. In Table 6, both systems Mode 1 and 2, have the same $t_{1}$ time but different $t_{2}$ time which means different $\Delta \mathrm{t}$ time. Interval time, $\Delta \mathrm{t}$ is $\mathrm{t}_{2}-\mathrm{t}_{1}$ in seconds. Mode 1 system responses took longer time to cool down compared to Mode 2. Worth to highlight the Mode 1 and Mode 2 give same results i.e. IL3, IL2 and CFL3 as their best systems. Figure 3 shows the responses for Mode 2 control.

Table 6. Comparison between Mode 2 control \& Mode 1

\begin{tabular}{lccc}
\hline System & $\mathbf{t}_{1}(\mathbf{s e c})$ & $\begin{array}{c}\Delta t(s e c) \\
\text { Mode 1 }\end{array}$ & $\begin{array}{c}\Delta t \text { (sec) } \\
\text { Mode 2 }\end{array}$ \\
\hline IL3 & 46.78 & 18.00 & 17.3 \\
IL2 & 68.78 & 27.60 & 18.1 \\
CFL3 & 86.78 & 85.40 & 29.1 \\
\hline
\end{tabular}

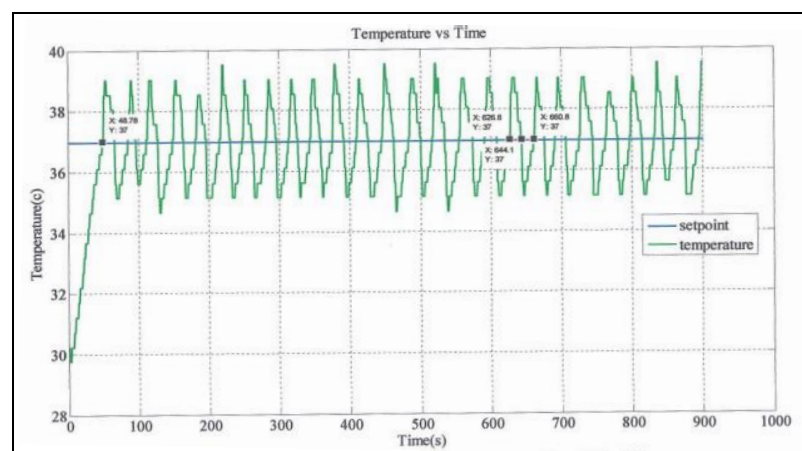

(a)

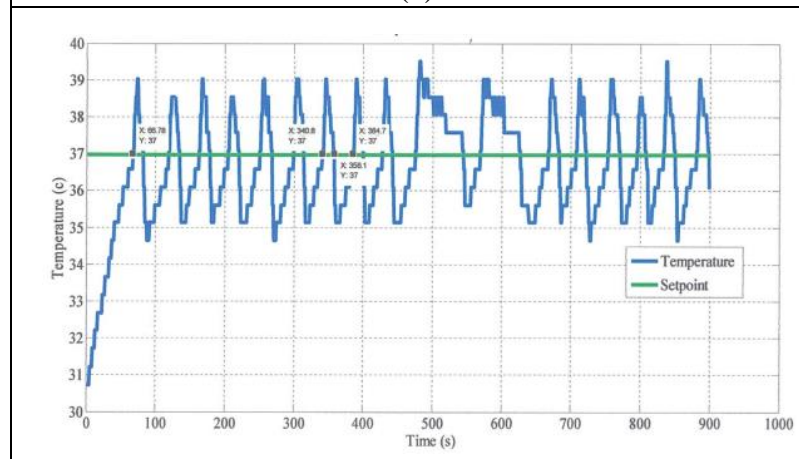

(b)

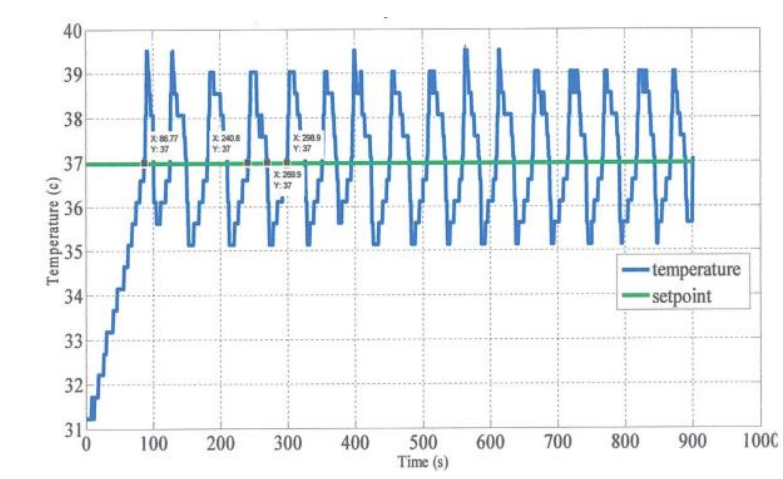

(c)

Fig. 3 - The experimental results for Mode 2 (a) IL3 System Response, (b) IL2 System Response, (c) CFL3 System Response 
Next, are the experiment results of all nine systems using Mode 3 control strategy. Mode 3 includes the control of ventilation fans only. Only in this mode, the bulbs were in ON mode when the fans are controlled. Mode 3 results are tabulated in Table 7.

LED took the longest time to reach Tset, and LED1 did not able to reach Tset at all. For this project, good temperature control performance means the system is able to reach its set point within a short time. IL 3 has the ability to reach the Tset. Using this control mode, the second best system performance was CFL3, followed by CFL2. The forth best was IL2. These results were different from Mode 1 and Mode 2 control.

Table 6. Experimental results for Mode 3 control

\begin{tabular}{lccc}
\hline System & $\mathbf{t}_{1}(\mathbf{s e c})$ & $\mathbf{t}_{2}(\mathbf{s e c})$ & $\boldsymbol{\Delta t}(\mathbf{s e c})$ \\
\hline IL3 & $\mathbf{3 0 . 7 8}$ & $\mathbf{4 4 . 0 7}$ & $\mathbf{1 3 . 2 9}$ \\
CFL3 & $\mathbf{3 8 . 7 8}$ & $\mathbf{5 0 . 0 7}$ & $\mathbf{1 1 . 2 9}$ \\
CFL2 & $\mathbf{5 6 . 7 8}$ & $\mathbf{6 8 . 0 7}$ & $\mathbf{1 1 . 2 9}$ \\
IL2 & 78.77 & 87.17 & 8.40 \\
CFL1 & 182.80 & 188.70 & 5.90 \\
LED3 & 382.80 & 388.60 & 5.80 \\
IL1 & 462.80 & 471.00 & 8.20 \\
LED2 & 612.80 & 620.60 & 7.80 \\
LED1 & - & - & - \\
\hline
\end{tabular}

From the plotted responses in Figure 4, it can also be observed that for all four systems, they oscillated at the same temperature range, i.e. maximum $39.5^{\circ} \mathrm{C}$ and minimum $34.5^{\circ} \mathrm{C}$. Although Mode 3 systems have higher oscillation margin, the resulted average temperature is approximately $37^{\circ} \mathrm{C}$.

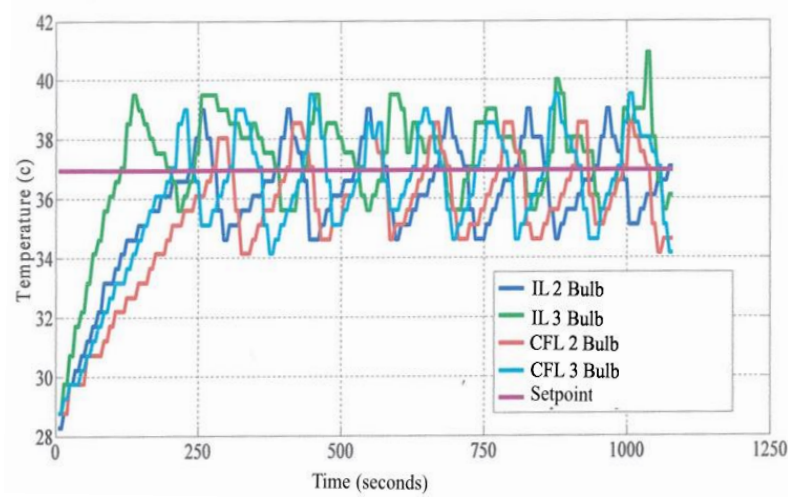

Fig. 3 - Incubator temperature, T(oC) vs time, $t$ (sec) for four types of system using Mode 3 control

\section{Conclusion}

From the experiment, it can be concluded that to design an incubator using light bulb as its thermal source, it is the best to design the system with bulb type IL. This design is proposed based from the experiments conducted. The experiment uses an incubator with a size $26 \mathrm{~cm}(\mathrm{~W}) \times 38 \mathrm{~cm}(\mathrm{~L}) \times 26 \mathrm{~cm}(\mathrm{H})$ made of Styrofoam. Based from the results, control Mode 3 will be the best to design the system with good temperature control performance. The experiment shows that IL3 with Mode 3 control will have better transient response where $\mathrm{t}_{2}$ and $\Delta \mathrm{t}$ are shorter.

To improve the results, next step is to use Sum Squared Error (SSE) or Sum of Absolute Errors (SAE) to determine each temperature control performance. The best parameter to indicate the temperature control is in good performance is by referring to its time response specification such as rise time, settling time, percentage overshoot, steady state error. Since the results are not settle, SSE or SAE will be the best performance indices for the system.

\section{ACKNOWLEDGEMENTS}

The authors wish to acknowledge the Ministry of Education (KPT), Malaysia and Universiti Teknikal Malaysia Melaka, for supporting this research. 


\section{References}

[1] Dr Jacquie Jacob, "Raising Chickens for Egg Production”, Online magazine extention.org, May 2015. Article available online at http://articles.extension.org/pages/71004/raising-chickens-for-egg-production

[2] C.A. Aliza, F.Y. Chin, M.G. Mariam, S.H. Ching, V. Sakthivelu, "Development of Passive Quarter Car Suspension Prototype", Applied Mechanics and Materials Vol 761,015, pp 238-244.

[3] Jason Yao, "Modeling and Control of a Tungsten-Bulb Heated Incubator: Teaching Controls Theory in a General Engineering Program", 122 ${ }^{\text {nd }}$ ASEE Annual Conference \& Exposition, 2015, Paper ID: 12762, American Society for Engineering Education.

[4] Poultry Hub Australia, "Chicken Embryo Development", 2013. Video available online at https://youtu.be/PedajVADLGw

[5] R. A. Ernst, F. A. Bradley, M. E. Delany, and U. K. Abbott, "Common Incubation Problems : Causes and Remedies," pp. 1-6, 2004.

[6] W. Xinling, "Avian Hatching Monitor and Control System Based on 1-Wire Sensor Groups," 2008 Int. Work. Educ. Technol. Train. 2008 Int. Work. Geosci. Remote Sens., pp. 357-360, Dec. 2008.

[7] Wilson HR, "Physiological requirements of the developing embryo: temperature and turning.", pp.145-156, 1990.

[8] Nick A. French, "The critical importance of incubation temperature", AVIAN Biology Research, 2(1/2), pp.5559, 2009.

[9] Y. Tahara, K.Obara, “A Novel Shell-less Culture System for Chick Embryos Using a Plastic Film as Culture Vessels", Journal of Poultry Science, Vol.51(3), pp.307-312, 2014.

[10] Chris Meyer, "Lightbulb Efficiency Comparison Chart", 2015. Available: https://greatercea.org/lightbulbefficiency-comparison-chart/

[11] J. Velagic, N.Osmic, K.Lutvica, N.Kadic, "Incubator System Identification and Temperature Control With PLC and HMI", ELMAR Proceedings, 2010. 